\title{
Vision and Representation in Architecture and Mathematics
}

\author{
Kim Williams ${ }^{1}$
}

Published online: 3 July 2020

(c) Kim Williams Books, Turin 2020

\begin{abstract}
Editor-in-Chief Kim Williams examines the role of vision and interpretation in establishing relationships between architecture and mathematics, and introduces the articles in Nexus Network Journal vol. 22 no. 3 (2020).
\end{abstract}

When we talk about relationships between architecture and mathematics, very often we talk about how an abstract or virtual system (mathematics) underlines a system of built elements (architecture). What may be less obvious is that our methods for identifying the two systems and integrating them are very often based on vision. Our sense of vision allows us to perceive and isolate certain aspects of an entity-a room, a building, a city-which we can then analyse in relation to other elements or concepts in order arrive at an understanding of what it is that we are actually seeing. We are able, for example, to isolate shape and distortion, or pattern and scaling. The step that follows our vision is that of interpreting what we see. Our interpretations might take the form of drawings that allow us to see the building as we would never see it (an undistorted view from on high, with the roof removed), or models that are capable of abstracting the information on which we wish to focus.

Three of the papers in this issue are concerned with questions of perspective, a discipline that proposes a distorted representation of a scene or an object in order to fool the eye. In "Baldassare Peruzzi and Theatrical Scenery in Accelerated Perspective", Philip Steadman takes us to the theatres of the Renaissance where the stage and scenery were shallow, but the sets give illusions of much deeper spacestypically piazzas and receding streets surrounded by buildings-providing evidence that Sebastiano Serlio learned the technique of accelerated perspective from Baldassare Peruzzi.

Antonio Ampliato and Eduardo Acosta, in "On the Use of Perspective in a Drawing Attributed to Diego Siloé", carefully analyse and reconstruct geometrically a sketch of a Renaissance urban setting that displays a masterly use of one-point perspective by the sixteenth-century Spanish architect.

Kim Williams

kwb@kimwilliamsbooks.com

1 Corso Regina Margherita, 72, 10153 Turin, Italy

Birkhäuser 
As we know, geometrical perspective was codified in the Renaissance, but some forms of perspective are found in much earlier works of art. The question of how perspective was actually developed from ancient times to the Renaissance was the subject of a long debate. In " $N$-Dimensional Space and Perspective: The Mathematics behind the Interpretation of Ancient Perspective" Laura Carlevaris shows how a late-nineteenth-century superposition of the retinal vision of Euclid, combined with the curved geometries of Gauss and Riemann, opened the door for a new analysis of ancient forms of perspective.

Modelling is an important aid in interpreting what is seen. In "Modelling Based on a Certified Level of Accuracy: The Case of the Solimene Façade" Adriana Rossi demonstrates how advances in surveying techniques based on high resolution 3D laser scanners and photographic data make it possible to measure the deviation between the numerical experimental model and the mathematical model.

In "The House of the White Man: A Mathematical Description", Elena Marchetti and Luisa Rossi Costa also use modelling to reconstruct mathematically the forms they saw in an icon of the Bauhaus period designed by Johannes Iten.

Mathematical modelling is also used by Alberto Lastra and Manuel de Miguel, in "Geometry of Curves and Surfaces in Contemporary Chair Design". The long tradition of chair design has been profoundly influenced by the aesthetics of architecture and improvements in modern engineering. As they explain, the knowledge of the implicit equations defining certain varieties allows verification of whether an object belongs to such a variety or not, whereas the use of parametrizations associated with the so-called regular varieties allows construction of the object, at least locally.

Three-dimensional models also play an important role in analysis. In "Modelling the Stars of the Sagrada Familia", María de los Desamparados López de Briñas Ferragut examines the star shapes present in the façade of Gaudí's iconic cathedral in Barcelona. Her analysis reveals that their organic appearance is actually based on a hidden morphology that can be explained by using theoretical models of star polyhedra.

Measuring can also be an invaluable aid to the visualisation and representation of objects, as it allows us to quantify what we see. In "Triangulation Algorithms for Generating As-Is Floor Plans", Filipe Jorge da Silva Brandão, Alexandra Paio and Adriano Lopes demonstrate how empirical triangulation methods, traditionally used by architects and other building professionals in surveying building interiors, can be adapted for the development of semi-automated workflow of room surveys. The goal is to allow non-professionals to participate in the design process by measuring their own spaces.

Sometimes the object of measurement is something other than physical dimensions. In "Measuring Visual Complexity of Sedad Eldem's SSK Complex and Its Historical Context: A Comparative Analysis Using Fractal Dimensions ", Mario Lodeweik Lionar and Özgür Ediz measured the fractal dimension of an icon of Turkish design in order to verify claims of visual "harmony" between the architectural design of the 1960s and the urban context into which it is set.

Measurements and measuring devices can even play a symbolic role. In "Gromatic Images from New Discoveries in Pompeii”, Luisa Ferro, Giulio Magli and 
Massimo Osanna present mosaics representing a tool called the "groma" used by Roman agrimensores, brought to light thanks to recent excavations. Their research shows that these unexpected images are related to the geometry of the house they ornamented, and even to the cosmos.

The three contributions in this issue's "Geometer's Angle" column take us from two dimensions to higher dimensions.

As we know, from the Renaissance through the Baroque, enormous time and effort were invested in understanding the methods to correctly and geometrically construct images in perspective. In "Parallelogrammum Prosopographicum" Gregorio Astengo presents a surprising case study for a history of early modern architectural representation, describing a device invented in the 1700 s aimed at doing the opposite, that is, at overcoming the visual effects of perspectival foreshortening.

In "Hand Drawing in the Definition of the First Digital Curves" Fernando Díaz Moreno examines the work of two automotive engineers, Pierre Bézier and Paul de Casteljau, who believed that manual strokes to draw curves were the most effective model for digital curves, and the inclusion of that model in the present day in the software used by architects.

In "Islamic Geometric Patterns in Higher Dimensions", Sam Moradzadeh and Ahad Nejad Ebrahimi develop Islamic geometric patterns from planar coordinates to three or higher dimensions through their repeat units, thanks to a novel approach that uses a method of tessellation that generates 3D Islamic patterns called "interior polyhedral stellations".

Publisher's Note Springer Nature remains neutral with regard to jurisdictional claims in published maps and institutional affiliations.

Kim Williams received her degree in Architectural Studies from the University of Texas in Austin. She became interested in mathematics and architecture while writing Italian Pavements: Patterns in Space (Anchorage Press, 1997) about the role of decorated pavements in the history of Italian architecture, and it has been her field of research ever since. She is the founder and director of the international, interdisciplinary conference series "Nexus: Relationships Between Architecture and Mathematics", and is the founder and coeditor-in-chief (with Michael Ostwald) of the Nexus Network Journal. Her latest publication is Daniele Barbaro's Vitruvius of 1567 (Birkhäuser, 2019). 